\title{
The essential oils component $p$-cymene induces proton leak through Fo-ATP synthase and uncoupling of mitochondrial respiration
}

This article was published in the following Dove Press journal:

Journal of Experimental Pharmacology

24 August 201 I

Number of times this article has been viewed

\author{
José BA Custódio ${ }^{1,2}$ \\ Mariana $\vee$ Ribeiro ${ }^{1,2}$ \\ Filomena SG Silva ${ }^{1,2}$ \\ Marisa Machado 3,4 \\ M Céu Sousa ${ }^{3,4}$
}

'Center for Neuroscience and Cell Biology, ${ }^{2}$ Laboratory of Biochemistry, Faculty of Pharmacy, ${ }^{3}$ Center of Pharmaceutical Studies, ${ }^{4}$ Laboratory of Microbiology, Faculty of Pharmacy, University of Coimbra, Portugal
Correspondence: José BA Custódio Faculdade de Farmácia, Piso 5- Gabinete8, Pólo das Ciências da Saúde, Azinhaga de Santa Comba, 3000-548 Coimbra, Portugal Email custodio@ci.uc.pt
Abstract: Essential oils can be used as antimicrobial, antioxidant, and anticarcinogenic agents or to preserve and give flavors to foods. The activity of phenolic-rich essential oils has been observed in fractions containing thymol and carvacrol which show synergistic effects with their precursor $p$-cymene. Their mode of action is related to several targets in the cell but specific mechanisms of activity and cytotoxic effects remain poorly characterized. Given the importance of mitochondria for cellular functions and their critical role in a vast number of diseases, this work evaluated the effects of $p$-cymene on mitochondrial functions. It was observed that $p$-cymene did not change the oxygen consumption by respiratory chain (state 2 respiration). However, $p$-cymene decreased the mitochondrial membrane potential $(\Delta \psi)$, depressed the rate of ADP phosphorylation (state 3), and stimulated the oxygen consumption after phosphorylation of ADP (state 4). The respiratory control ratio (state 3/state 4) was decreased as a consequence of the inhibition of state 3 and stimulation of state 4 respiration but the ADP/O index remained unaltered as well as the mitochondrial $\mathrm{Ca}^{2+}$ fluxes. Moreover, $p$-cymene did not induce mitochondrial membrane disruption but depressed the $\Delta \psi$, and the stimulatory effect observed on state 4 , similar to the effect observed on state 2 respiration plus ATP, was inhibited by oligomycin. These effects suggest that $p$-cymene allows a proton leak through the Fo fraction of the phosphorylative system, changing the mitochondrial proton motive force and ATP synthesis capacity. Therefore, these data suggest mitochondria as a target for $p$-cymene toxicity action mechanisms.

Keywords: antimicrobial, proton leak, ATP synthase, $p$-cymene, essential oils, food additive, mitochondrial respiration, uncoupling

\section{Introduction}

p-Cymene (1-isopropyl-4-methylbenzene) (Figure 1) is a natural hydrocarbon that is a component of essential oils, ie, natural products extracted from vegetable materials. For example, the essential oils obtained from oregano and thyme, traditional Mediterranean spices, are characterized by a very high content of monoterpenes such as $p$-cymene (trace to 52\%), $\gamma$-terpinene (2\%-52\%), thymol (trace to 64\%), and carvacrol $(1 \%-80 \%){ }^{1,2}$ However, $p$-cymene occurs in the oils of many other gymnospermic and angiospermic plants. It is metabolized by the liver and the major $p$-cymene metabolite is cuminyl alcohol. ${ }^{3}$ Furthermore, formation of $p$-cymene as a dead-end metabolite from certain nonaromatic monoterpenes has been observed in anoxic enrichment cultures ${ }^{4,5}$ and degradation has been also demonstrated with anaerobic and aerobic bacteria. ${ }^{6}$

In vitro studies have demonstrated that the monoterpene $p$-cymene can be used as an antimicrobial against the Gram-positive bacterium Staphylococcus aureus 


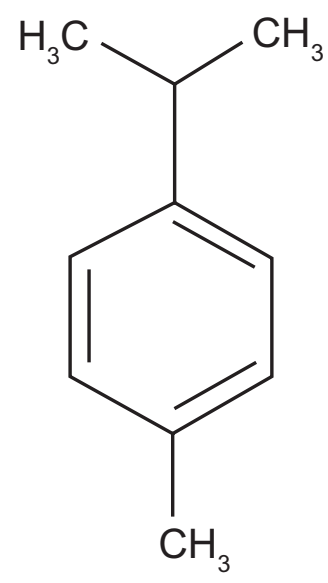

Figure I Chemical structure of p-cymene (I-isopropyl-4-methylbenzene).

and the Gram-negative Escherichia coli, ${ }^{7,8}$ and synergistic effects have been observed between both monoterpenes carvacrol and thymol, main components of some essential oils and responsible for their activity, ${ }^{9}$ and their precursor $p$-cymene. ${ }^{10-12}$ Furthermore, different studies have shown that $p$-cymene and its derivative monoterpenes are efficient antioxidant and anticarcinogenic agents, and they are approved in the United States and Europe to preserve and to give specific flavors to foods and feeds. ${ }^{11}$ However, $p$-cymene has been reported to be less effective against food-related pathogens.

The precise target of the antimicrobial action of $p$-cymene and derivatives has not yet been fully established but it has been reported that the mode of action involves several targets in the cell. $p$-Cymene has been shown to have lipolytic properties. In fact, it has been reported that the antimicrobial effects of $p$-cymene and derivatives carvacrol, thymol, and $\gamma$-terpinene may result, partially at least, from a gross perturbation of the lipid fraction of the plasmic membrane, acting by disrupting the cytoplasmic membrane, ${ }^{7}$ with loss of its high impermeability for protons and bigger ions. The disturbance of membrane integrity compromises its functions not only as a barrier but also as a matrix for enzymes and as an energy transducer. ${ }^{13}$ Changes in the fatty acid composition of bacterial cell membranes (an increase in unsaturated fatty acids) and changes in membrane fluidity have been observed. ${ }^{14}$ Therefore, the hydrophobicity enables them to partition in the lipids of the cell membrane and mitochondria, rendering them permeable and leading to leakage of cell contents. In addition to the effects on the membrane integrity and transmembrane potential, treatment with this monoterpenes induced depletion of the intracellular ATP levels when bacterial cells were exposed to sublethal concentrations. ${ }^{15}$
Moreover, recent studies have found that these compounds are effective against Leishmania. ${ }^{16}$ The mechanism of leishmanicidal action of these compounds could be related to their interference in the mitochondrial bioenergetic processes of Leishmania.

The range of concentrations of $p$-cymene used as antimicrobial additives in food and feed $(0.25-1.25 \mathrm{mM})^{12,17}$ remains poorly characterized relative to specific mechanisms involved in the antimicrobial action and cytotoxic effects in humans. Moreover, the mechanisms of action proposed are not specific to microorganism metabolic pathways and could affect the mammalian cells. Thus, to ensure the safe and successful use of monoterpenes essential oil components as food additives and therapeutical drugs, toxicity studies with these compounds should be performed. Given the importance of mitochondria to basic cellular functions, including production of ATP, their role in controlling pathways of intracellular $\mathrm{Ca}^{2+}$ homeostasis, ${ }^{18}$ apoptotic and necrotic cell death, ${ }^{19}$ and the critical role of mitochondrial impairment in a vast number of disorders, ${ }^{20,21}$ the aim of this work was to evaluate whether $p$-cymene modulates mitochondrial functions. Although, it is difficult to extrapolate the data obtained with mitochondrial studies to the in vivo situation in humans, the concentrations of $p$-cymene used in this study ( $\leq 100 \mathrm{nmol} / \mathrm{mg}$ of protein or $25-100 \mu \mathrm{M}$ ) were significantly lower than those used to preserve foods and with antimicrobial activity. ${ }^{12,17}$ It is, therefore, possible that the mitochondrial damage by $p$-cymene, shown in the present study, ie, proton leak through the Fo fraction of mitochondrial ATP synthase with perturbations in mitochondrial proton motive force and loss of ATP synthesis capacity required to support the regulation of several cell functions, might occur in humans and perhaps contribute to some side effects.

\section{Materials and methods Chemicals}

p-Cymene, bovine serum albumin (BSA), 4-(2-hydroxyethyl)piperazineethansulfonic acid (HEPES), ethylenediaminetetraacetic acid (EDTA), and oligomycin were purchased from Sigma Chemical Co. (St Louis, MO). Ethyleneglicol-bis- $(\alpha-$ aminoethylether) $\mathrm{N}, \mathrm{N}^{\prime}$-tetraacetic acid (EGTA) and sucrose were from Merck (Darmstadt, Germany). All other chemicals were commercial products of the highest purity grade available. Solutions were prepared in deionized ultra pure water.

\section{Isolation of rat liver mitochondria}

Mitochondria were prepared from Wistar rats (250-300 g) by differential centrifugation as described elsewhere..$^{22,23}$ Rats were euthanized by decapitation and liver was removed, 
finely minced, and washed in ice-cold isolation medium containing $250 \mathrm{mM}$ sucrose, $0.5 \mathrm{mM}$ EGTA, $0.5 \mathrm{mM}$ EDTA, $10 \mathrm{mM}$ HEPES, $\mathrm{pH} 7.4$, and $0.1 \%$ (w/v) fatty acid-free bovine serum albumin (BSA). ${ }^{24}$ Tissue fragments were quickly homogenized with a motor-driven Teflon Potter homogenizer in the presence of ice-cold isolation medium. Liver homogenate was centrifuged at $800 \mathrm{~g}$ for 10 minute (IEC B-20A centrifuge) at $4^{\circ} \mathrm{C}$ and mitochondria recovered from the supernatant by centrifugation at $10,000 \mathrm{~g}$ for 10 minutes. The mitochondrial pellet was resuspended in washing medium using a paintbrush and centrifuged twice at $10,000 \mathrm{~g}$ for 10 minute before obtaining a final mitochondrial suspension. EGTA and defatted BSA were omitted from the final washing medium, which was adjusted to $\mathrm{pH} 7.2 .{ }^{25}$ Mitochondrial protein content was determined by the Biuret method ${ }^{26}$ using BSA as the protein standard.

\section{Mitochondrial respiration}

Mitochondrial respiration was measured polarographically using a Clark-type oxygen electrode (Yellow Springs Instruments, $\mathrm{OH})^{27}$ inserted into a $1 \mathrm{~mL}$ water-jacketed sealed glass chamber with constant magnetic stirring maintained at $30^{\circ} \mathrm{C}$, and connected to a suitable recorder. Mitochondria ( $1 \mathrm{mg}$ protein $/ \mathrm{mL}$ ) were suspended in a standard respiratory medium containing $130 \mathrm{mM}$ sucrose, $50 \mathrm{mM} \mathrm{KCl,} 5 \mathrm{mM}$ $\mathrm{MgCl}_{2}, 0.1 \mathrm{mM}$ EGTA, $5 \mathrm{mM} \mathrm{KH} \mathrm{PO}_{4}$, and $5 \mathrm{mM}$ HEPES, $\mathrm{pH}$ 7.4. The initial rate of oxygen consumption (state 2 respiration) was recorded following addition of glutamate plus malate $(5 \mathrm{mM} / 2.5 \mathrm{mM})$, and state 3 rate of respiration was induced by the subsequent addition of $200 \mathrm{nmol}$ of ADP. After a measurable state 4 rate respiration (ie, the rate after ADP is phosphorylated), a second pulse of ADP was added but the phosphorylative cycle was inhibited by adding $1 \mu \mathrm{g}$ of oligomycin (Olig) (st4-olig). $p$-Cymene (in DMSO solution, up to $0.2 \%$ of the experiment's final volume) and ATP (100 nmol/mg protein) were incubated with mitochondria for 3 minutes prior to the addition of substrate. Control experiments were performed in the presence of $0.2 \%$ DMSO. FCCP-stimulated respiration was induced with the addition of $1 \mu \mathrm{M}$ FCCP added 2 minutes after mitochondria energization. Respiratory control ratios $(\mathrm{RCR}=$ state $3 /$ state 4 respiration $)$, respiratory states, and $\mathrm{ADP} / \mathrm{O}$ (the ratio between the amount of ADP added and the $\mathrm{O}_{2}$ consumed during state 3 respiration) were determined according to Chance and Williams. ${ }^{28}$

\section{Mitochondrial membrane potential determination}

The mitochondrial membrane potential $(\Delta \Psi)$ was monitored by evaluating transmembrane distribution of the lipophilic cation tetraphenylphosphonium $\left(\mathrm{TPP}^{+}\right)$with a $\mathrm{TPP}^{+}$-selective electrode prepared according to Kamo et $\mathrm{al}^{29}$ using a Ag/ $\mathrm{AgCl}_{2}$-saturated electrode as reference (model MI 402; Microelectrodes, Inc, Bedford, NH). TPP $^{+}$uptake was measured from the decreased $\mathrm{TPP}^{+}$concentration in the medium sensed by the electrode. The potential difference between the selective electrode and the reference electrode was measured with an electrometer and recorded continuously in a Linear 1200 recorder. The voltage response of the $\mathrm{TPP}^{+}$electrode to $\log \left[\mathrm{TPP}^{+}\right]$was linear with a slope of $59 \pm 1$, in good agreement with the Nernst equation. Reactions were carried out in a chamber with magnetic stirring in $1 \mathrm{~mL}$ of the standard medium (130 mM sucrose, $50 \mathrm{mM} \mathrm{KCl,} 2.5 \mathrm{mM} \mathrm{MgCl}_{2}$, $2.5 \mathrm{mM} \mathrm{KH}_{2} \mathrm{PO}_{4}, 100 \mu \mathrm{M}$ EGTA, and $5 \mathrm{mM}$ Hepes, $\mathrm{pH}$ 7.4) supplemented with $3 \mu \mathrm{M} \mathrm{TPP}{ }^{+}{ }^{27}$ A matrix volume of $1.1 \mu \mathrm{L} / \mathrm{mg}$ protein was assumed. No correction was made for the "passive" binding contribution of $\mathrm{TPP}^{+}$to the mitochondrial membranes because the purpose of the experiments was to show relative changes in potentials rather than absolute values. As a consequence, we can anticipate a slight overestimation of $\Delta \Psi$ values.

Mitochondria $(1 \mathrm{mg} / \mathrm{mL})$ in the standard respiratory medium were energized by the addition of $5 \mathrm{mM}$ glutamate/2.5 mM malate. After a steady-state distribution of $\mathrm{TPP}^{+}$had been reached (ca. 1 minute of recording) ADP was added and $\Delta \Psi$ fluctuations recorded. $p$-Cymene and ATP ( $100 \mathrm{nmol} / \mathrm{mg}$ protein) were preincubated for 3 minutes prior to mitochondria energization.

\section{Measurement of mitochondrial swelling}

Mitochondrial osmotic volume changes were followed by monitoring the decrease in absorbance (light-scattering) at $540 \mathrm{~nm}$ with a Perkin Elmer, Lambda 6 UV/VIS spectrophotometer. ${ }^{23}$ The reactions were performed with $1 \mathrm{mg}$ of mitochondrial protein in $2 \mathrm{~mL}$ of a reaction medium containing $200 \mathrm{mM}$ sucrose, $10 \mathrm{mM}$ Tris-Mops ( $\mathrm{pH} 7.4$ ), $1 \mathrm{mM} \mathrm{K \textrm {K } _ { 2 }} \mathrm{PO}_{4}$ and $10 \mu \mathrm{M}$ EGTA. $p$-Cymene was added to mitochondrial suspensions in the absence and presence of respiratory substrates and preincubated for 3 minutes at $30^{\circ} \mathrm{C}$.

\section{Evaluation of mitochondrial permeability transition pore}

Mitochondrial $\mathrm{Ca}^{2+}$ fluxes were measured by monitoring the changes in $\mathrm{Ca}^{2+}$ concentration in the reaction medium using the hexapotassium salt of the fluorescence probe Calcium Green 5-N. ${ }^{30}$ Mitochondria ( $\left.0.5 \mathrm{mg}\right)$ were suspended in $2 \mathrm{~mL}$ of reaction medium containing $200 \mathrm{mM}$ sucrose, $10 \mathrm{mM}$ Tris-Mops, 1 mM KH $\mathrm{PO}_{4}, 10 \mu \mathrm{M}$ EGTA, $2 \mu \mathrm{M}$ rotenone, 
and $0.5 \mu \mathrm{g}$ oligomycin/ml, $\mathrm{pH} 7.4$, supplemented with $100 \mathrm{nM}$ of Calcium Green 5-N. Fluorescence was recorded continuously in a water-jacketed cuvette holder at $30^{\circ} \mathrm{C}$ using a Perkin-Elmer spectrofluorometer LS-50 B with an excitation wavelength of $506 \mathrm{~nm}$ (slit $4 \mathrm{~nm}$ ) and an emission wavelength of $532 \mathrm{~nm}$ (slit $6 \mathrm{~nm}$ ). ${ }^{25}$ Opening of mitochondrial permeability transition pore (MPT) was induced by addition of $\mathrm{Ca}^{2+}(60 \mathrm{nmol} / \mathrm{mg}$ protein $)$ and energization with succinate $(5 \mathrm{mM})$ and prevented by preincubation with cyclosporin A (CsA) $(0.85 \mu \mathrm{M})$. $p$-Cymene $(25 \mathrm{nmol} / \mathrm{mg}$ protein $)$ was incubated with mitochondria for 3 minutes before $\mathrm{Ca}^{2+}$ addition and energization with succinate.

\section{Statistical data analysis}

The results were expressed as the mean \pm SD of 4 of 6 independent experiments and the data were analyzed using oneway ANOVA followed by the Tukey post-test, for multiple comparisons. A $P$ value $<0.05$ was considered statistically significant.

\section{Results}

This study evaluated the effects of $p$-cymene in the mitochondrial respiratory chain and in the phosphorylation efficiency of rat liver mitochondria. The energization of mitochondria with glutamate/malate in the absence of $p$-cymene induced a slight increase in the oxygen consumption (state 2 respiration) (Figure 2A) due to the activation of the respiratory chain. The preincubation of mitochondria with $25,50,75$ and $100 \mathrm{nmol}$ $p$-cymene/mg of protein did not induce a significant increase in state 2 respiration compared with mitochondria incubated in the absence of $p$-cymene (Control) (Figure 2A).

The addition of ADP to mitochondria induced strong oxygen consumption (56.6 $\mathrm{nmol} \mathrm{O} / \mathrm{min} / \mathrm{mg}$ of protein) (state 3 respiration) (Figure 2B, Control) in contrast to that observed in state 2 respiration $\left(8.4 \mathrm{nmol} \mathrm{O}_{2} / \mathrm{min} / \mathrm{mg}\right.$ of protein) (Figure 2B, Control). The preincubation of mitochondria with 25 and $50 \mathrm{nmol} p$-cymene/mg of protein did not decrease significantly the rate of ADP phosphorylation (state 3 respiration) (Figure 2B). However, state 3 respiration was significantly decreased when mitochondria were incubated with $p$-cymene at concentrations $>75 \mathrm{nmol} / \mathrm{mg}$ of protein (Figure $2 \mathrm{~B}$ ), suggesting that $p$-cymene affects the phosphorylation capacity of rat liver mitochondria.

When all ADP was phosphorylated, mitochondria returned to state 4 respiration $\left(8.4 \mathrm{nmol} \mathrm{O}_{2} / \mathrm{min} / \mathrm{mg}\right.$ of protein) (Figure 2C) where the oxygen consumption is lower than in state 3 (Figure 2B) and similar to the observed in state 2 respiration ( $8.4 \mathrm{nmol} \mathrm{O}_{2} / \mathrm{min} / \mathrm{mg}$ of protein) (Figure $2 \mathrm{~A}$ ).
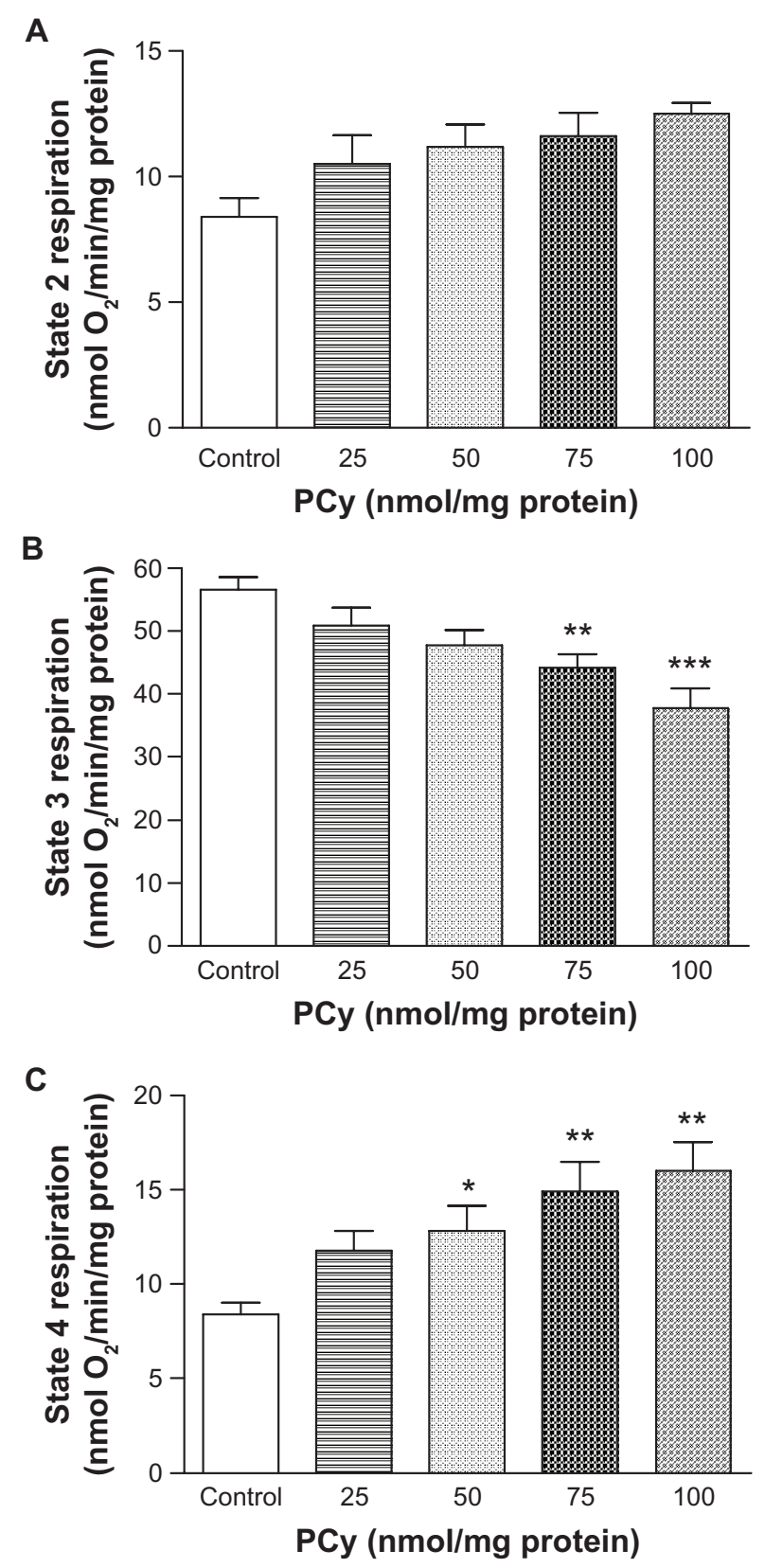

Figure 2 Effect of $p$-cymene (PCy) on the respiratory states 2 (A), 3 (B) and 4 (C) of liver mitochondria induced by glutamate/malate. Mitochondrial respiration rates were determined by $\mathrm{O}_{2}$ consumption using a Clark-type electrode.

Notes: The data represent the means \pm SD of 6 independent experiments. $* P<0.05 ; * * P<0.01 ; * * * P<0.001$ vs control.

The preincubation of $25 \mathrm{nmol} p$-cymene/mg of protein did not induce significant alterations in state 4 respiration. However, $p$-cymene at concentrations $>50 \mathrm{nmol} / \mathrm{mg}$ of protein added in vitro to rat liver mitochondria induced a significant stimulation in state 4 respiration (Figure 2C), suggesting that $p$-cymene induces a proton leak through the components of the mitochondrial inner membrane.

To evaluate the depressive effect on phosphorylation capacity of liver mitochondria observed in presence of 
p-cymene, the RCR (state 3/state 4) and ADP/O indices were determined. As seen in Figure 3A, $p$-cymene concentrations $\geq 25 \mathrm{nmol} / \mathrm{mg}$ of protein significantly decreased the RCR compared with control mitochondria. This effect of $p$-cymene occurred essentially as a consequence of the inhibition of state 3 and stimulation of state 4 respiration. Although we observed a decrease in respiratory state 3 , the $\mathrm{ADP} / \mathrm{O}$ ratio of mitochondria incubated with $p$-cymene was not statistically different compared with the control (Figure 3B).

The stimulation of state 4 respiration induced by $p$-cymene could result from a membrane proton permeabilization as a consequence of either mitochondrial membrane disruption or proton shuttling. In order to clarify this mechanism, the effects of $p$-cymene on the integrity of the mitochondrial membrane were evaluated by monitoring the decrease in absorbance (light scattering) at $540 \mathrm{~nm}$ (Figure 4). The addition of Triton X-100, which induces disruption of the cellular membrane integrity, strongly decreased the light-scattering of mitochondrial suspension reflecting an extensive swelling of
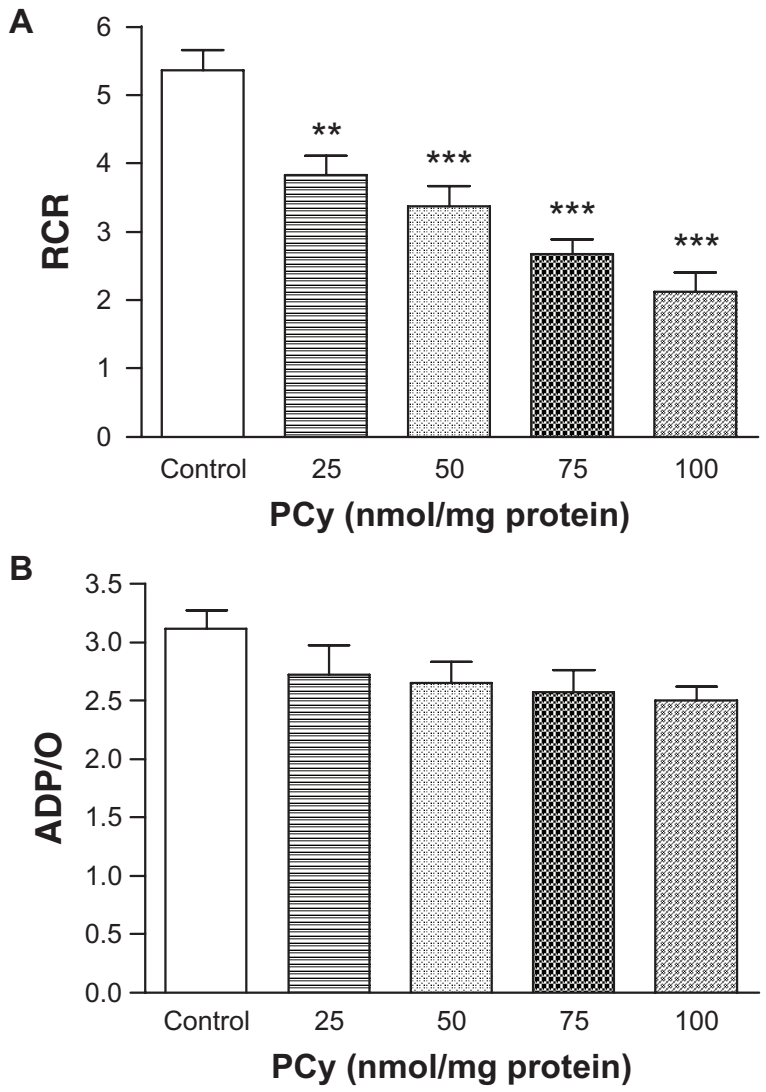

Figure 3 Effect of $p$-cymene $(P C y)$ on respiratory control ratio $(R C R)(\mathbf{A})$ and ADP/O ratio $(\mathbf{B})$.

Notes: Indices were determined as described in Materials and methods and values are expressed as means $\pm S D$ of 6 independent experiments. ${ }^{*} * P<0.01$; $* * * P<0.001$ vs control.

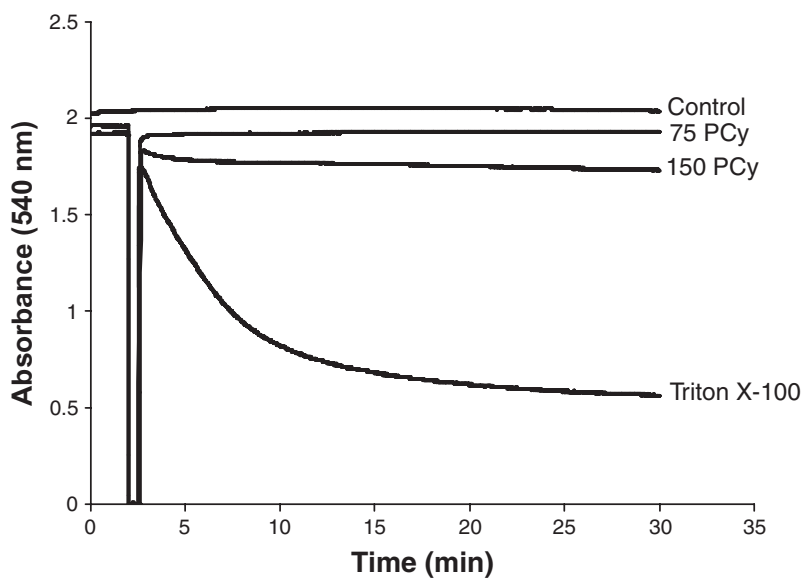

Figure 4 Effects of p-cymene (PCy) on mitochondrial swelling. The traces, obtained by following the light scattering at $540 \mathrm{~nm}$, are typical of 4 separate experiments with different mitochondrial preparations.

mitochondria (Figure 4). The preincubation of mitochondria with $p$-cymene at concentrations that stimulate state 4 respiration, 75 and $150 \mathrm{nmol} p$-cymene/mg of mitochondrial protein, did not significantly decrease the light-scattering of non-energized mitochondria compared with the effects of Triton X-100, suggesting that $p$-cymene in the concentrations studied did not induce mitochondrial membrane disruption (Figure 4).

Although we did not observe a statistically significant stimulation of respiratory state 2 induced by $p$-cymene on mitochondria energized with glutamate/malate (before ADP addition) (Figure 2A), respiratory state 4 (after ADP phosphorylation) was stimulated by this compound (Figure $2 \mathrm{C}$ ). When we evaluated the effect of $p$-cymene on state 2 respiration in the presence of ATP, it was observed that the addition of $p$-cymene at concentrations $<50 \mathrm{nmol} / \mathrm{mg}$ of protein did not induce a significant increase in state 2 respiration (Figure 5A). However, mitochondria co-incubated with ATP in the presence of 75 and $100 \mathrm{nmol} p$-cymene/mg of protein stimulated state 2 respiration compared with control, ie, in the presence of ATP alone (Figure 5A). These results are similar to those observed in state 4 respiration (Figure 2C), suggesting an increased stimulatory effect in the presence of exogenous ATP or synthesized by the phosphorylation system.

To clarify the different effects of ATP on $p$-cymeneinduced respiratory changes, further experiments were performed with oligomycin, an inhibitor of proton translocation through the Fo fraction of ATP synthase (Figure 5B). The addition of oligomycin to mitochondria preincubated with $25 \mathrm{nmol} p$-cymene/mg of protein did not induce a significant decrease in state 4 respiration $(P>0.05)$. At concentrations $>50 \mathrm{nmol} p$-cymene/mg of protein, the addition 
A
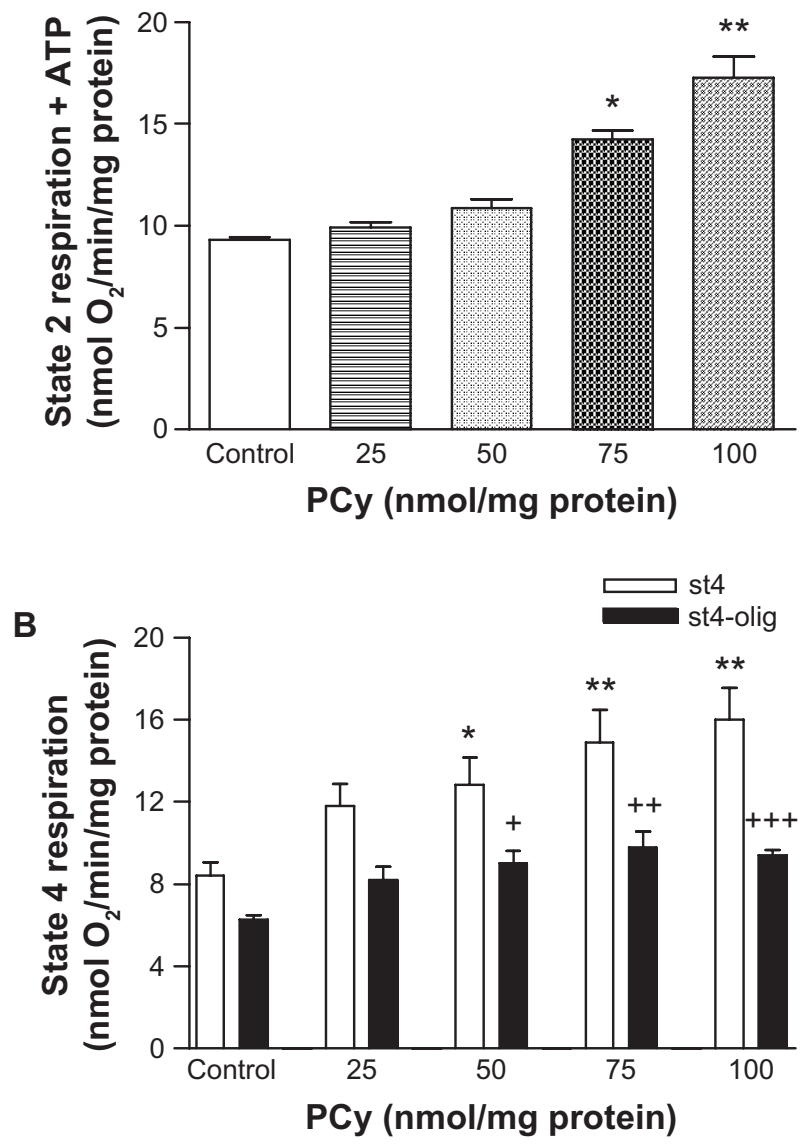

Figure 5 Effect of $p$-cymene (PCy) on state 2 plus ATP (A) and on state 4 respiration in the presence of oligomycin (st4-olig) (B). State 2 respiration was determined after energization of liver mitochondria with glutamate/malate and state 4 respiration after phosphorylation of ADP. State 4 respiration in the presence of oligomycin (st4-olig) was induced by the addition of ADP and oligomycin after the steady state of oxygen consumption characteristic of state 4 respiration had been reached. Notes: The data shown represent the means \pm SD of 6 independent experiments. ${ }^{* P}<0.05$; $* * P<0.01$ vs control; ${ }^{+} P<0.05$; ${ }^{+} P<<0.01$; ${ }^{++} P<0.00$ I vs state 4 in the absence of oligomycin (st4).

of oligomycin to mitochondria during respiratory state 4 decreased $\mathrm{O}_{2}$ consumption stimulated by $p$-cymene as a function of concentration (Figure 5B). These results suggest that $p$-cymene in the presence of ATP induces $\mathrm{H}^{+}$leak through the Fo fraction of complex $\mathrm{V}$ of the respiratory chain.

$\Delta \Psi$ is fundamental for the phenomenon of oxidative phosphorylation, the conversion of ADP to ATP via ATP synthase. The mitochondrial respiratory chain pumps $\mathrm{H}^{+}$out of the mitochondrial matrix across the inner mitochondrial membrane. The $\mathrm{H}^{+}$gradient originates an electrochemical potential $(\Delta \mathrm{p})$ resulting in a $\mathrm{pH}(\Delta \mathrm{pH})$ and a voltage gradient $(\Delta \Psi)$ across the mitochondrial inner membrane. Dissipation of $\Delta \mathrm{p}$ by permeabilization of membrane to $\mathrm{H}^{+}$impairs oxidative phosphorylation efficiency of mitochondria.

$\Delta \Psi$ developed by mitochondria after energization with glutamate/malate was $\approx-223 \mathrm{mV}$ (negative inside) (Table 1). $p$-cymene did not induced significant alteration in $\Delta \Psi$ and ADP phosphorylative cycle at concentrations $<50 \mathrm{nmol} / \mathrm{mg}$ protein. However, we observed that at concentrations above $75 \mathrm{nmol} / \mathrm{mg}$ protein the depolarization induced by ADP and the lag phase (time necessary for ADP phosphorylation) were significantly changed and the effects were potentiated in the presence of ATP (Table 1).

When MPT was induced by $\mathrm{Ca}^{2+}$ in the presence of inorganic phosphate, we observed that isolated mitochondria incubated with $40 \mathrm{nmol} \mathrm{Ca}{ }^{2+} / \mathrm{mg}$ protein rapidly accumulated and retained the $\mathrm{Ca}^{2+}$ from the medium (Figure 6). In contrast, when mitochondria were incubated with $60 \mathrm{nmol} \mathrm{Ca}{ }^{2+} / \mathrm{mg}$ protein they accumulated $\mathrm{Ca}^{2+}$ from the medium but after some time they released the accumulated $\mathrm{Ca}^{2+}$, this effect being prevented by $\mathrm{CsA}$ addition. The presence of $p$-cymene did not significantly affect the effect of $\mathrm{Ca}^{2+}$ in any of the conditions tested (Figure 6).

\section{Discussion}

According to previous studies, the antimicrobial effect of monoterpenes such as thymol, carvacrol, $p$-cymene, and $\gamma$-terpinene may result, partially at least, from a gross perturbation of the lipid fraction of the plasmic membrane of the microorganism..$^{13,31}$ In addition to being related to the physicochemical characteristics of the compounds (such as lipophilicity and water solubility), this effect seems to be dependent on the lipid composition and net surface charge of membranes. ${ }^{7}$ Moreover, it has been reported that these monoterpenes decreased the intracellular ATP pool in different microorganisms and increased the extracellular ATP, also indicating a disruptive action on the cytoplasmic membrane. ${ }^{32}$ However, this unspecific mechanism involved in the antimicrobial action of these monoterpenes, also used to preserve and give specific flavors to foods, could contribute to cytotoxic effects on mammalian cells and the putative side effects remain poorly characterized. Mitochondria serve as sensors of the xenobiotic-induced toxicity that ultimately leads to cellular disassembly. ${ }^{20}$

In this work, we report the effects of $p$-cymene, a thymol and carvacrol precursor, on rat liver mitochondria to clarify its effects on bioenergetic functions and membrane integrity of mitochondria. It was observed that $p$-cymene did not affect state 2 respiration induced by glutamate/malate, but decreased state 3 and stimulated state 4 respiration (Figure 2). The different effect on states 2 and 4 of respiration suggest that $p$-cymene effects depend on the energetic charge, ie, the ATP levels, and that $p$-cymene induces damage in the mitochondrial membrane permeability. This permeabilization of membrane to protons, as indicated by the stimulation of state 4 , is 
Table I Effects of $p$-cymene (PCy) on oxidative phosphorylation parameters of rat liver mitochondria

\begin{tabular}{lllllll}
\hline PCy (nmol/mg protein) & Control & $\mathbf{2 5}$ & $\mathbf{5 0}$ & $\mathbf{7 5}$ & $\mathbf{1 0 0}$ & $\mathbf{7 5 + A T P}$ \\
\hline$\Delta \psi(-\mathrm{mV})$ & $223 \pm 1.85$ & $219 \pm 2.15$ & $216 \pm 2.34$ & $202 \pm 2.99 *$ & $194 \pm 1.38^{* *}$ & $180 \pm 4.87 * * *$ \\
Depolarization by ADP $(-\mathrm{mV})$ & $32.4 \pm 1.93$ & $31.9 \pm 1.75$ & $32.1 \pm 2.53$ & $28.3 \pm 2.10^{*}$ & $23.9 \pm 1.34^{* *}$ & $15.3 \pm 2.89 * * *$ \\
Lag phase (min) & $1.32 \pm 0.07$ & $1.34 \pm 0.15$ & $1.42 \pm 0.11$ & $2.06 \pm 0.15 * *$ & $2.67 \pm 0.35 * *$ & $\infty$ \\
\hline
\end{tabular}

Notes: Values are expressed as mean \pm SD of 4 independent experiments. $* P<0.05$; $* * P<0.0$; $* * * P<0.00$ I compared with control.

not a consequence of mitochondrial membrane disruption or change in lipid-protein interactions, since this monoterpene induced only a slight swelling of non-energized mitochondria (Figure 4). Supporting this assumption is the observation that the stimulation of state 4 was inhibited by oligomycin (Figure 5A), an inhibitor of proton translocation through the Fo fraction of ATP synthase, indicating that $p$-cymene induced membrane permeabilization to protons by affecting the conformational structure of Complex V proteins, namely the Fo fraction of ATP synthase. Based on this observation and the absence of any significant change in mitochondrial volume (Figure 4), we may propose that the cell toxicity of $p$-cymene could not be related to disruption of the cell membrane but to the changes in cellular ATP levels.

The possible mechanisms of inhibition of energy regeneration capacity are related to the decrease in $\Delta \psi$ and ADP phosphorylation rate also inferred from the decrease in state 3 respiration (Figure 2B), increasing the time required to ATP synthesis (Table 1) and promoting a rapid decline in cellular ATP pools. Moreover, RCR (state 3/state 4) (Figure 3A) ratio was also decreased due to the inhibition of state 3 and stimulation of state 4 respiration, indicating an uncoupling effect of $p$-cymene on the oxidative phosphorylation system. Although not statistically significant but in agreement with these observations, the changes in the ADP/O ratio (Figure 3B) indicate a decrease in the phosphorylative capacity rate of mitochondria induced by $p$-cymene according to the increase in the lag phase (Table 1). The proton leak through the Fo fraction of mitochondrial ATP synthase promoted by $p$-cymene (Figure 5B) explains the increase in state 4 respiratory rate, collapse of $\Delta \Psi$, and consequent uncoupling effect on the phosphorylation system, with perturbations in mitochondrial proton motive force and loss of ATP synthesis capacity required to support the regulation of several cell functions (Table 1). Therefore, although it is common for reviewers of spice oils to ascribe their cytotoxic effects to

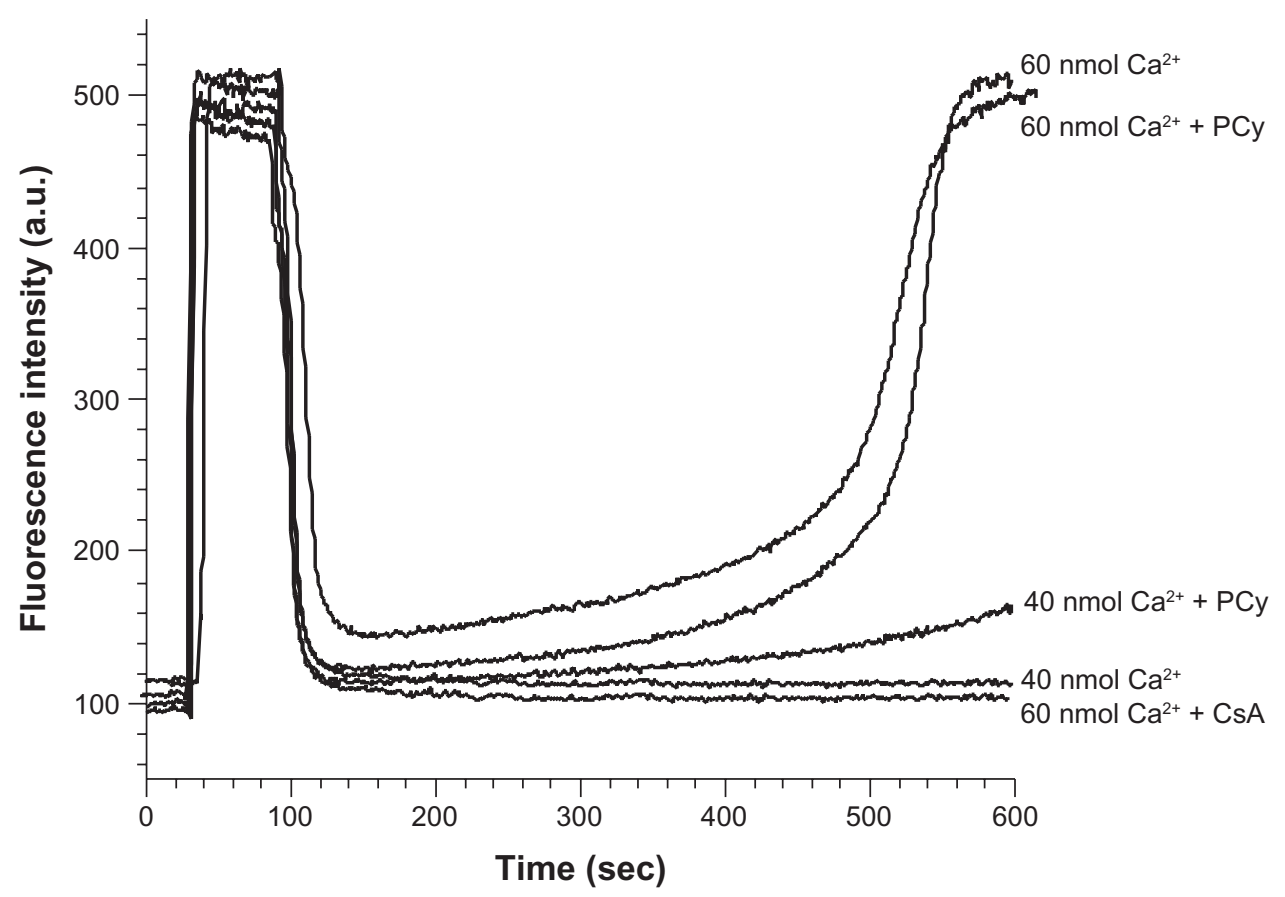

Figure 6 Effect of p-cymene (PCy) on $\mathrm{Ca}^{2+}$ fluxes of mitochondria isolated from rat liver. Freshly isolated mitochondria were incubated at $0.25 \mathrm{mg} / \mathrm{mL}$ under standard conditions as described in the Materials and Methods section. Standard medium was supplemented with different concentrations of $\mathrm{Ca}^{2+} \mathrm{I}$ minute before mitochondria energization with $5 \mathrm{mM}$ succinate. Cyclosporin $\mathrm{A}(\mathrm{CsA})(0.85 \mu \mathrm{M})$ or $\mathrm{p}$-cymene $\left(25 \mathrm{nmol} / \mathrm{mg}\right.$ protein) were added to the reaction medium 3 minutes prior to Ca ${ }^{2+}$ addition. The traces are typical of 6 independent experiments. 
interactions with the cell membrane, and this action cannot be discounted, the effects on energy generation clearly could play a major role in the cell toxicity of $p$-cymene.

\section{Disclosure}

The authors declare no conflicts of interest.

\section{References}

1. Baratta TM, Dorman DJH, Deans GS, Biondi DM, Ruberto G. Chemical composition, antimicrobial and antioxidative activity of laurel, sage, rosemary, oregano and coriander essential oils. Journal of Essential Oil Research. 1998;10:618-627.

2. Russo M, Galletti GC, Bocchini P, Carnacini A. Essential oil chemical composition of wild populations of Italian oregano spice (Origanum vulgare ssp. hirtum (Link) Ietswaart): A preliminary evaluation of their use in chemotaxonomy by cluster analysis. 1. Inflorescences. J Agric Food Chem. 1998;46:3741-3746.

3. Pass GJ, McLean S, Stupans I, Davies NW. Microsomal metabolism and enzyme kinetics of the terpene $p$-cymene in the common brushtail possum (Trichosurus vulpecula), koala (Phascolarctos cinereus) and rat. Xenobiotica. 2002;32:383-397.

4. Harder J, Probian C. Microbial degradation of monoterpenes in the absence of molecular oxygen. Appl Environ Microbiol. 1995;61: 3804-3808.

5. Häner A, Höhener P, Zeyer J. Degradation of $p$-xylene by a denitrifying enrichment culture. Appl Environ Microbiol. 1995;61:3185-3188.

6. Harms G, Rabus R, Widdel F. Anaerobic oxidation of the aromatic plant hydrocarbon $p$-cymene by newly isolated denitrifying bacteria. Arch Microbiol. 1999;172:303-312.

7. Cristani M, D'Arrigo M, Mandalari G, et al. Interaction of four monoterpenes contained in essential oils with model membranes: implications for their antibacterial activity. J Agric Food Chem. 2007;55: 6300-6308.

8. Shapira R, Mimran E. Isolation and characterization of Escherichia coli mutants exhibiting altered response to thymol. Microb Drug Resist. 2007; 13:157-165.

9. Lambert RJW, Skandamis PN, Coote PJ, Nychas GJ. A study of the minimum inhibitory concentration and mode of action of oregano essential oil, thymol and carvacrol. J Appl Microbiol. 2001;91:453-462.

10. Vardur-Unlu G, Candan F, Sokmen A, et al. Antimicrobial and antioxidant activity of the essencial oil and methanol extracts of Thymus pectinatus Fisch. et Mey. Var. pectinatus (Lamiaceae). J Agric Food Chem. 2003;51:63-67.

11. Burt SA. Essential oils: Their antibacterial properties and potential applications in foods - A review. Int J Food Microbiol. 2004;94:223-253.

12. Kiskó G, Roller S. Carvacrol and p-cymene inactivate Escherichia coli O157:H7 in apple juice. BMC Microbiol. 2005;5:36-45.

13. Gill AO, Holley RA. Disruption of Escherichia coli, Listeria monocytogenes and Lactobacillus sakei cellular membranes by plant oil aromatics. Int J Food Microbiol. 2006;108:1-9.

14. Di Pasqua R, Hoskins N, Betts G, Mauriello G. Changes in membrane fatty acids composition of microbial cells induced by addiction of thymol, carvacrol, limonene, cinnamaldehyde, and eugenol in the growing media. J Agric Food Chem. 2006;54:2745-2749.

Journal of Experimental Pharmacology

\section{Publish your work in this journal}

The Journal of Experimental Pharmacology is an international, peerreviewed, open access journal publishing original research, reports, reviews and commentaries on all areas of laboratory and experimental pharmacology. The manuscript management system is completely online and includes a very quick and fair peer-review system.
15. Oussalab M, Caillet S, Lacroix M. Mechanism of action of Spanish oregano, Chinese cinnamon, and savory essential oils against cell membranes and walls of Escherichia coli O157:H7 and Listeria monocytogenes. J Food Prot. 2006;69:1046-1055.

16. Monzote L, Garcia M, Montalvo AM, Scull R, Miranda M, Abreu J. In vitro activity of an essential oil against Leishamania donovani. Phytother Res. 2007;21:1055-1058.

17. Burt SA, van der Zee R, Koets AP, et al. Carvacrol induces heat shock protein 60 and inhibits synthesis of flagellin in Escherichia coli O157:H7. Appl Environ Microbiol. 2007;73:4484-4490.

18. Brookes PS, YoonY, Robotham JL, Anders MW, Sheu SS. Calcium, ATP, and ROS: a mitochondrial love-hate triangle. Am J Physiol Cell Physiol. 2004;287:C817-C833.

19. Orrenius S, Gogvadze V, Zhivotovsky B. Mitochondrial oxidative stress: Implications for cell death. Annu Rev Pharmacol Toxicol. 2007;47:143-183.

20. Wallace KB, Starkov AA. Mitochondrial targets of drug toxicity. Annu Rev Pharmacol Toxicol. 2000;40:353-388.

21. Wallace DG. A mitochondrial paradigm of metabolic and degenerative diseases, aging, and cancer: a dawn for evolutionary medicine. Annu Rev Genet. 2005;39:359-407.

22. Gazotti P, Malmstron K, Crompton M. A Laboratory Manual on Transport and Bioenergetics. New York: Springer Verlag; 1979.

23. Custódio JBA, Moreno AJM, Wallace KB. Tamoxifen inhibits induction of the mitochondrial permeability transition by $\mathrm{Ca}^{2+}$ and inorganic phosphate. Toxicol Appl Pharmacol. 1998;152:5384-5394.

24. Cardoso CMP, Custódio JBA, Almeida LM, Moreno AJM. Mechanisms of the deleterious effects of tamoxifen on mitochondrial respiration rate and phosphorylation efficiency. Toxicol Appl Pharmacol. 2001;176: $145-152$.

25. Moreira PI, Custódio JBA, Nunes E, et al. Estradiol affects liver mitochondrial function in ovariectomized and tamoxifen-treated ovariectomized female rats. Toxicol Appl Pharmacol. 2007;221:102-110.

26. Gornall AG, Bardawill CJ, David MM. Determination of serum proteins by means of the biuret reaction. J Biol Chem. 1949;177:751-766.

27. Moreira PI, Custódio JBA, Moreno AJM, Oliveira CR, Santos MS. Tamoxifen and estradiol interact with the flavin mononucleotide site of complex I leading to mitochondrial failure. J Biol Chem. 2006;281: 10143-10152.

28. Chance B, Williams GR. Respiratory enzymes in oxidative phosphorylation. VI. The effects of adenosine diphosphate on azide-treated mitochondria. J Biol Chem. 1956;221:477-489.

29. Kamo N, Muratsugu M, Hongoh R, Kobatake Y. Membrane potential of mitochondria measured with an electrode sensitive to tetraphenyl phosphonium and relationship between proton electrochemical potential and phosphorylation potential in steady state. J Membr Biol. 1979;49: 105-121.

30. Rajdev S, Reynolds IJ. Calcium green-5N, a novel fluorescent probe for monitoring high intracellular free $\mathrm{Ca}^{2+}$ concentrations associated with glutamate excitotoxicity in cultured rat brain neurons. Neurosci Lett. 1993;162:149-152.

31. Brul S, Coote P. Preservative agents in foods: mode of action and microbial resistance mechanisms. Int J Food Microbiol. 1999;50:1-17.

32. Helander IM, Alakomi HL, Latva-Kala K, et al. Characterization of the action of selected essential oil components on gram-negative bacteria. J Agric Food Chem. 1998;46:3590-3595.

Visit http://www.dovepress.com/testimonials.php to read real quotes from published authors. 